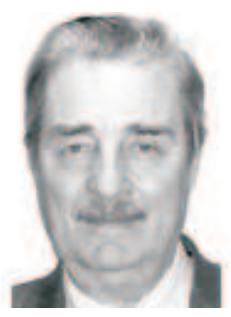

MAPAХTAНОВ

Михаил Константинович (МГТУ им. Н.Э. Баумана)

MARAKHTANOV Mikhail Konstantinovich (Moscow, Russian Federation, Bauman Moscow State Technical University)

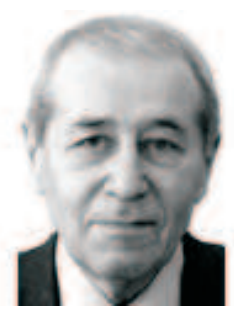

КЛИМЕНКО

Георгий Константинович (МГТУ им. Н.Э. Баумана)

KLIMENKO

Georgiy Konstantinovich (Moscow, Russian Federation, Bauman Moscow State Technical University)

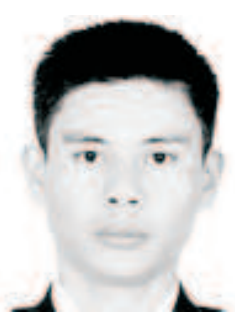

чЖО Вин Наинг (МГТУ им. Н.Э. Баумана)

KYAW Win Naing (Moscow, Russian Federation, Bauman Moscow State Technical University)
Исследование характеристик шероховатости покрытия, нанесенного методом плазменного напыления

\author{
М.К. Марахтанов, Г.К. Клименко, В.Н. Чжо
}

Поверхности, образованные методом плазменного напыления порошкового материала, обычно взаимодействуют с другими поверхностями или средами и условия этого взаимодействия существенно зависят от качества напыленной поверхности, в частности, от ее шероховатости. В исследовании поставлена задача определения связи между гранулометрическим составом порошка и шероховатостью покрытия. Проанализированы гранулометрический состав порошка напыляемого материала диоксида ииркония и шероховатость поверхности покрытия, полученного методом плазменного напыления. Измерен профиль поверхности покрытия с помощью профилографа и определено распределение размеров выступов зерен на поверхности покрытия. Проведено сравнение размеров микронеровностей поверхности с размерами частии, исходного порошка, а также порошка, ускоренного плазменной струей и заторможкенного водой. Анализ результатов сравнения позволяет сделать вывод о качественном соответствии размеров микронеровностей и размеров частии, порошка, а также о возможности прогнозирования шероховатости напыленной поверхности. Установленные связи позволят управлять качеством напыленных поверхностей в зависимости от поставленных требований.

Ключевые слова: гранулометрический состав, плазменное напыление, порошковый материал, шероховатость поверхности.

\section{Study of roughness characteristics of a coating deposited by plasma spraying}

\section{M.K. Marakhtanov, G.K. Klimenko, W.N. Kyaw}

Surfaces formed by plasma spraying of a powder material typically react with other surfaces or media, which greatly depends on the quality of the sprayed coating and, in particular, on the coated surface roughness. In this study, a relationship between the granulometric composition of a powder and the coated surface roughness is established. The particle size distribution of the zirconium oxide powder and the surface roughness of the plasma sprayed coating are analyzed. The coated surface profile is measured by the profilograph, and the grain size distribution on the coated surface is determined. The sizes of surface microasperities are compared with the sizes of particles comprising both the source powder and the powder accelerated by a plasma jet and decelerated by water. The results show that there is a qualitative agreement between the sizes of surfa- 
ce microasperities and powder particles, and it is possible to predict the sprayed surface roughness. The established relationships make it possible to control the quality of sprayed surfaces according to technological requirements.

Keywords: granulometric composition, plasma spraying, powder material, surface roughness.

$\prod$ окрытия, образованные методом плазриала, имеют, как правило, шероховатую поверхность [1]. Для снижения шероховатости поверхности требуется специальная обработка, например, механическая, тепловое оплавление и т. П. Причины образования шероховатости поверхности известны и понятны, но количественные оценки связи качества поверхности с характеристиками порошка и параметрами процесса напыления изучены недостаточно. Целью настоящего исследования является выявление связи шероховатости поверхности покрытия с характеристиками напыляемого материала, плазмы и покрытия, придания самой поверхности заданных свойств.

В работах [2-4] рассмотрено нанесение на стальную поверхность покрытия из порошка диоксида циркония, которое обычно используется в качестве теплозащитного материала.

Важнейшими критериями качества поверхности являются прочность сцепления покрытия с подложкой и отсутствие пористости покрытия [5]. Пористость покрытия зависит от соотношения размеров шероховатости и толщины покрытия. Отсутствие пористости обеспечивается повышением плотности наносимого слоя и толщиной покрытия или оплавлением поверхности, которое требует дополнительной обработки образца. В данной работе исследовалась связь шероховатости поверхности покрытия с размерами частиц напыляемого порошка.

Порошок наносился с помощью плазмотрона типа ПУН-1 в потоке воздушной плазмы [6]. Сила тока плазмотрона составляла 350 А при напряжении $120 \ldots 140$ В. Температура плазмы на выходе из плазмотрона достигала $5200 \mathrm{~K}$. Расстояние между плазмотроном и подложкой составляло 120 мм. Стальной диск диаметром 20 мм служил подложкой для покрытия и перемещался поперек плазменной струи со скоростью $0,1 \mathrm{~m} / \mathrm{c}$. Температура плазмы на выходе плазмотрона определялась калориметрическим методом.

Структура поверхности покрытия под микроскопом выглядит достаточно сплошной и однородной [7]. Однако при стереоскопическом обзоре на поверхности видны выступы и впадины разных форм и размеров, поддающихся измерению. Выступы имеют округлые формы и своими размерами соответствуют характерному размеру отдельной частицы или совокупности нескольких частиц в виде высоких наростов, напоминающих сталагмиты.

Причины появления выступов на поверхности покрытия различны. Для образования однородного гладкого покрытия все частицы порошка должны попадать на поверхность в расплавленном состоянии (в виде капель) и при соприкосновении с поверхностью растекаться по ней. Однако исследуемый диоксид циркония - тугоплавкий материал, требующий для расплавления гранул высокой температуры плазмы и сравнительно большего времени пребывания в потоке плазмы. Кроме того, напыляемый порошковый материал имеет частицы разного размера и различной формы, которые нагреваются и плавятся по-разному. Температура плазмы неоднородна по радиусу потока и частицы порошка на его периферии остаются не расплавленными. Поскольку поток перемещается относительно образца, последними на его поверхности остаются частицы из периферийной недогретой области потока.

Одними из основных факторов, определяющих качество процесса, являются размеры и гранулометрический состав исходного порошка и частиц осевших на поверхности, а также характерные размеры выступов на обработанной поверхности.

Гранулометрический состав исходного порошка определялся по изображениям частиц под микроскопом. Проба порошка наносилась на предметное стекло в один слой и затем определялись площадь и размеры каждой частицы, 
а также количество частиц в пробе по методике, представленной в работе [8]. При определении гранулометрического состава использовалось несколько проб с общим количеством частиц порядка 1 500. При этом пылевидная фракция с размерами частиц менее 10 мкм, составляющая незначительную часть массы порошка, из рассмотрения исключалась. Вид частиц под микроскопом и контуры частиц после обработки в плазме представлены на рис. 1.
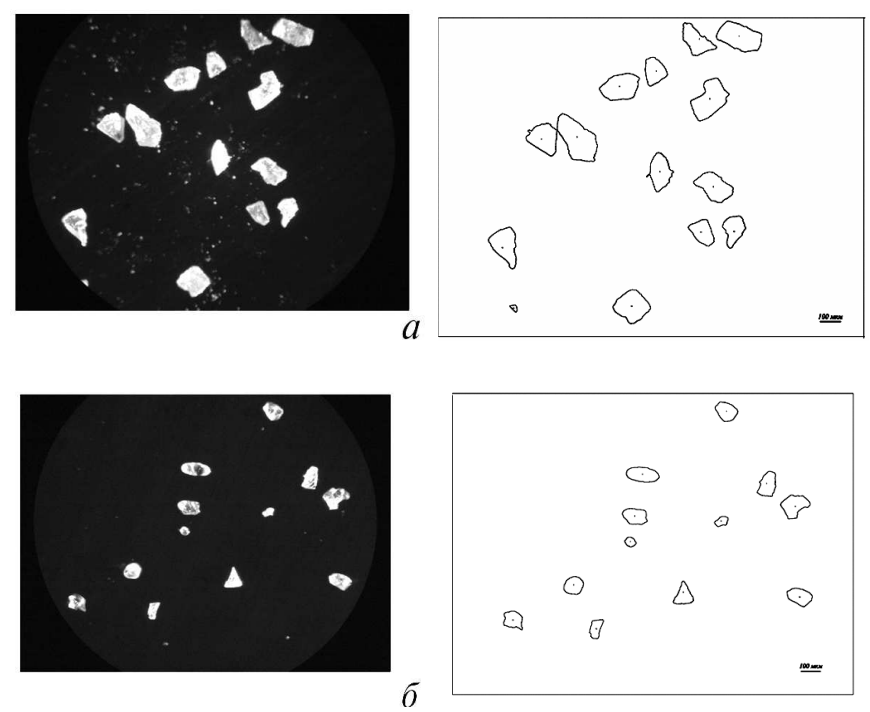

Puc. 1. Вид порошков диоксида циркония $\left(\mathrm{ZrO}_{2}\right)$ под микроскопом и контуры частиц для анализа гранулометрического состава:

$a-$ исходный порошок; $\sigma-$ порошок, прошедший струю плазмы и собранный в воду

Гранулометрический состав порошка, оседающего на образец, определялся косвенным методом. Для этого часть порошка, пролетавшего мимо образца, но рядом с ним, попадала в воду и собиралась после охлаждения. Остывший порошок фотографировался. Его размеры и форма принимались равными размерам частиц, оплавленных потоком плазмы. Гранулометрический состав исходного порошка и порошка после плазменной обработки представлен на рис. 2.

На основании приведенной диаграммы можно сделать вывод, что в потоке плазмы крупные частицы порошка диоксида циркония измельчаются, по-видимому, в результате термических напряжений.

Качество поверхности напыленного покрытия оценивалось величиной шероховатости,

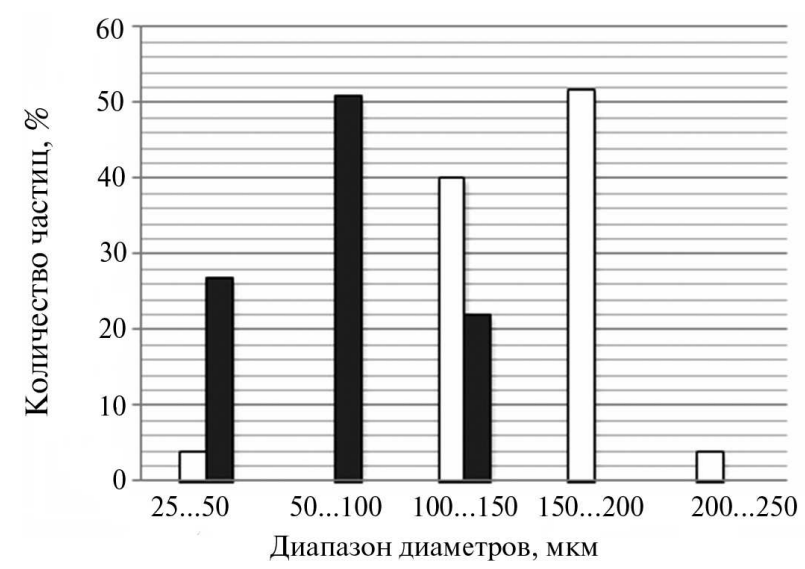

Puc. 2. Диаграмма гранулометрического состава частиц:

$\square-$ исходный порошок; $\mathbf{\square}-$ порошок, охлажденный водой после нагрева в плазме

которая измерялась с помощью профилографа [9] производства Московского инструментального завода «Калибр» модели 170622 (ГОСТ 2789-73) в нескольких плоскостях на базовой длине 6 мм. Характерный вид профилограммы приведен на рис. 3. Как видно на профилограмме разность высот выступов на поверхности покрытия имеет существенные размеры, соизмеримые как с габаритами наиболее крупных зерен порошка диоксида циркония, так и с измеряемой толщиной покрытия. Это позволяет предположить, что основой максимальных выступов на покрытии являются твердые зерна диоксида циркония, прошедшие поток плазмы без плавления, либо с частичным плавлением их поверхности, а впадины между выступами заполнили, по-видимому, расплавившиеся более мелкие частицы порошка. Размеры выступов на профиле поверхности в общем соответствует плоскому изображению поверхности, представленному на рис. 4.

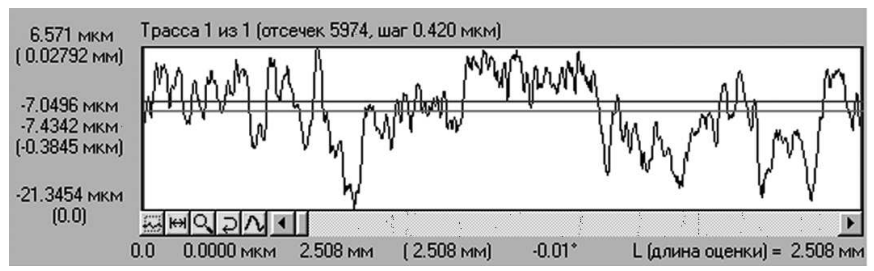

Рис. 3. Профилограмма поверхности образца.

По вертикальной оси отложенные значения отклонения профиля поверхности (шероховатости) от средней линии профиля; на горизонтальной (длина 2,5 мм) - контролируемой базы 


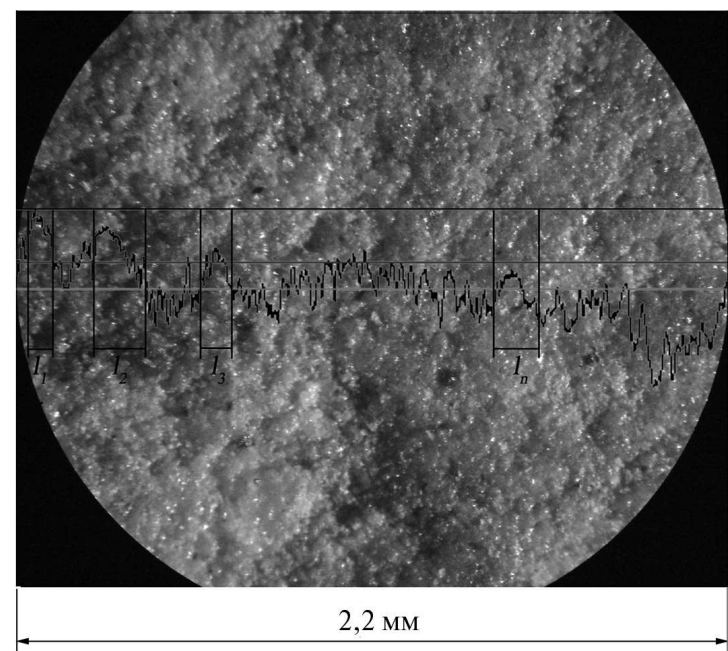

Puc. 4. Изображение поверхности

(× 100) и профилограмма поверхности

Обработка профилограмм показала, что разница размеров выступов на поверхности покрытия аналогична гранулометрическому составу порошка. По профилограмме, представленной на рис. 5, определялись размеры выступов профиля по средней линии профиля $l_{1}, l_{2}, \ldots, l_{n}$, которые интерпретировались как размеры частиц на поверхности. Такой подход позволил выявить на поверхности покрытия микрообъекты с характерным размером порядка единиц микрон.

Затем ширина выступов сравнивалась с размерами частиц исходного материала и с частицами порошка, попавшего в воду из плазменной струи. Результаты сравнения двух образцов поверхности представлены на рис. 6.

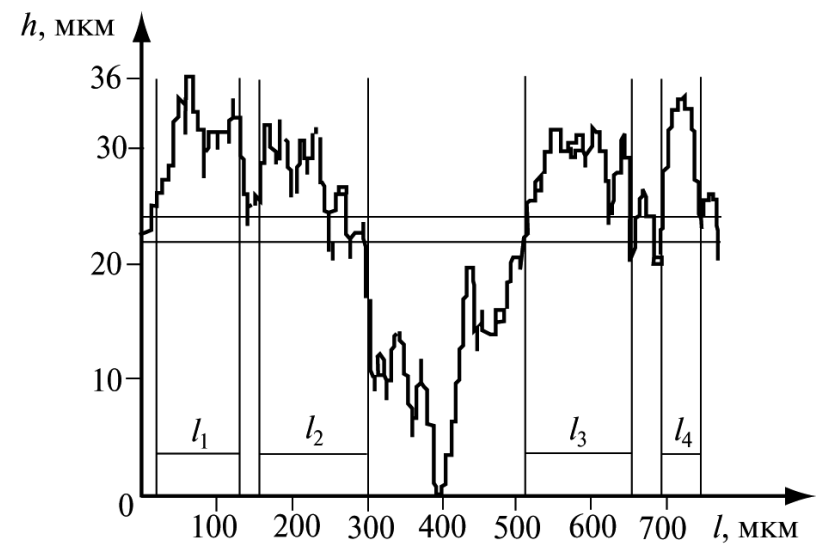

Рuc. 5. Профиль поверхности покрытия из диоксида циркония, нанесенного на стальную подложку

\section{Выводы}

1. Установлено, что порошок диоксида циркония, прошедший через струю плазмы, из-
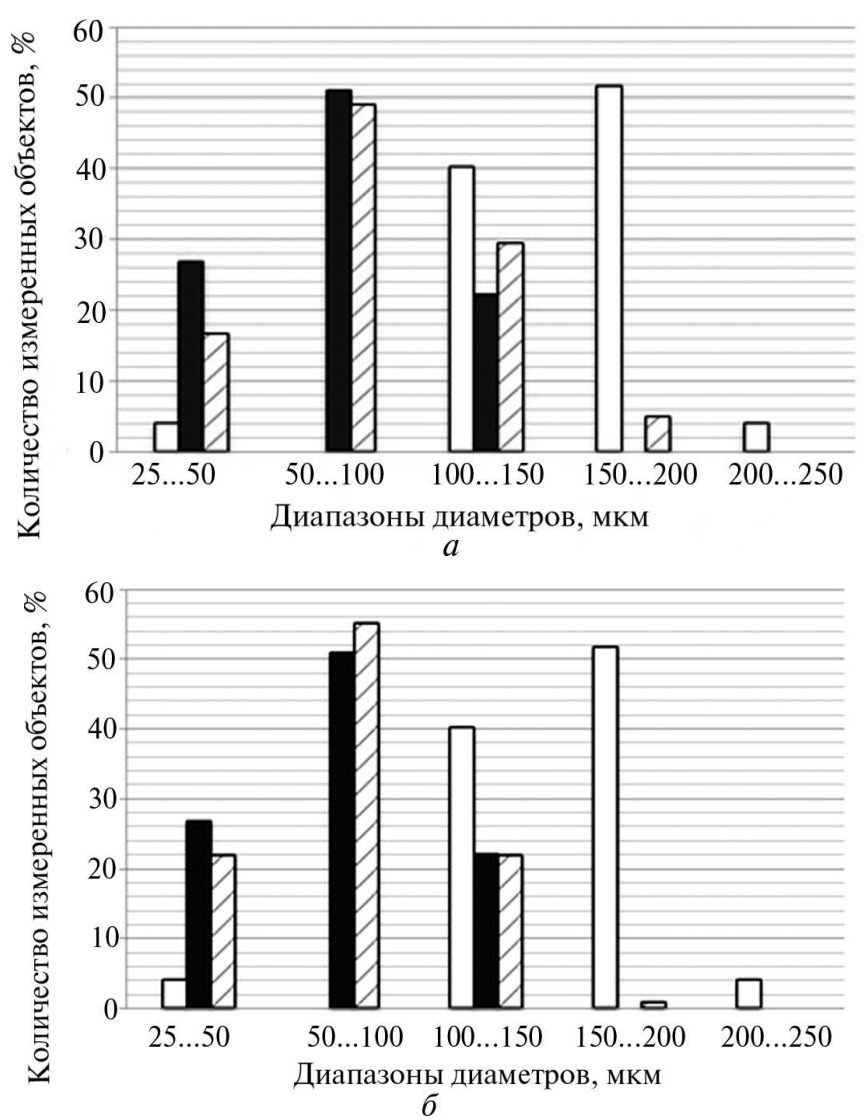

Puc. 6. Диаграммы гранулометрического состава исходного порошка в сравнении с размерами выступов на поверхности напыленной подложки:

\footnotetext{
$a$ - образец № $1 ; \sigma-$ образец № 2 ;

$\square-$ исходный порошок; $\mathbf{\square}-$ порошок,

охлажденный водой после нагрева в плазме;

$\square-$ средние размеры выступов, образовавшихся на напыленной поверхности второго образца
}

мельчается, в нем снижается количество крупных частиц и увеличивается число мелких (см. рис. 2), а также появляется пылевая фракция с размерами частиц на уровне 1 мкм, которые практические не улавливаются и не подаются учету.

2. На напыленной поверхности образуются выступы с широким диапазоном размеров. Измеренные значения размеров выступов по средней линии профиля позволяют оценить габариты образований на поверхности и сравнить их с размерами частиц исходного порошка, а также с размерами частиц в струе плазмы (рис. 6, a). Распределение размеров выступов примерно соответствует распределению частиц в струе плазмы, хотя размеры выступов меньше, чем размеры частиц исходного порошка. Наиболее вероятной причиной подобного расхождения габаритных размеров является неполное расплавление частиц, в результате чего 
твердое ядро частицы возвышается над поверхностью расплава в виде выступа. Происходит это вследствие низкой теплопроводности диоксида циркония, ограничивающей прогрев крупных частиц на всю глубину.

3. Появление мелкомасштабных шероховатостей на поверхности выступов связано, по мнению авторов статьи, с тем, что мелкие частицы из периферии плазменной струи налипают на расплавленную поверхность крупной частицы при ее перемещении в плазме.

4. Исследование причин и механизмов образования шероховатости поверхности позволит определить пути управления качеством поверхности напыленного покрытия.

\section{Литература}

[1] Кудинов В.В., Бобров Г.В. Нанесение покрытий напылением. Теория, технология и оборудование. Москва. Металлургия, 1992. 432 с.

[2] Кудинов В.В., Пекшев П.Ю., Белащенко В.Е., Солоненко О.П., Сафиуллин В.А. Нанесение покрытий плазмой. Москва, Наука, 1990. 408 с.

[3] Пузряков А.Ф. Теоретические основы технологии плазменного напыления. Москва, МГТУ им. Н.Э. Баумана, 2008. $360 \mathrm{c}$.

[4] Борисов Ю.С., Харламов Ю.А., Сидоренко С.Л., Ардатовская Е.Н. Газотермические покрытия из порошковых материалов. Справочник. Киев, Наукова Думка, 1987. 543 с.

[5] Freemantle M. Chemistry in action. Macmillan Education publ., London, 1987. 882 p.

[6] Коротеев А.С. Миронов В.М., Свирчук Ю.С. Плазмотроны. Конструкции, характеристики, расчет. Москва, Машиностроение, 1993. 296 с.

[7] Гончаров В.И., Карелина М.М., Уваров Л.Н., Костиков Н.К., Захаров В.В. Дефектоскопическое оборудование нового поколения повышенной информативности. Конверсия в машиностроении, 2006, № 2, с. 46-50.

[8] Дегтярев С.Д., Клименко Г.К., Ляпин А.А., Тасиц Е.И. Определения гранулометрического состава кварцевого по- рошка фотометрическим методом. Вестник МГТУ им. Н.Э. Баумана. Сер. Машиностроение, 2011, спец. вып. с. 49-57.

[9] Профилографы-профилометры контактные. ГОСТ 19300-86, Москва, Государственный стандарт СССР, 1987.

\section{References}

[1] Kudinov V.V., Bobrov G.V. Nanesenie pokrytii napyleniem. Teoriia, tekhnologiia i oborudovanie [Coating deposition. Theory, technology and equipment]. Moscow, Metallurgiia publ., 1992. $432 \mathrm{p}$.

[2] Kudinov V.V., Pekshev P.Iu., Belashchenko V.E., Solonenko O.P., Safiullin V.A. Nanesenie pokrytii plazmoi [Putting of plasma coatings]. Moscow, Nauka publ., 1990. 408 p.

[3] Puzriakov A.F. Teoreticheskie osnovy tekhnologii plazmennogo napyleniia [The theoretical basis of a plasma sputtering]. Moscow, Bauman Press, 2008. 360 p.

[4] Borisov Iu.S., Kharlamov Iu.A., Sidorenko S.L., Ardatovskaia E.N. Gazotermicheskie pokrytiia iz poroshkovykh materialov. Spravochnik [Thermal spray coating material powder. Handbook]. Kiev, Naukova Dumka, 1987. 543 p.

[5] Freemantle M. Chemistry in action. Macmillan Education publ., London, 1987. 882 p.

[6] Koroteev A.S. Mironov V.M., Svirchuk Iu.S. Plazmotrony. Konstruktsii, kharakteristiki, raschet [Plasmatrons. Designs, specifications, calculation]. Moscow, Mashinostroenie publ, 1993. $296 \mathrm{p}$.

[7] Goncharov V.I., Karelina M.M., Uvarov L.N., Kostikov N.K., Zakharov V.V. Defektoskopicheskoe oborudovanie novogo pokoleniia povyshennoi informativnosti [Flaw detection equipment of a new generation with increased informativity]. Konversiia v mashinostroenii [Conversion of engineering]. 2006, no. 2, pp. 46-50.

[8] Degtyarev S.D., Klimenko G.K., Liapin A.A., Tasits E.I. Opredeleniia granulometricheskgo sostava kvartsevogo poroshka fotometricheskim metodom [Definitions of granulometric structure of quartz powder powder photometrically]. Vestnik MGTU im. N.E. Baumana. Ser. Mashinostroenie [Herald of the Bauman Moscow State Technical University. Mechanical Engineering]. 2011, Special issue, pp. 49-57.

[9] GOST 19300-86. Profilografy-profilometry kontaktnye [State Standart 19300-86. Profilers-contact profilers]. Moscow, Gosudarstvennyi standart SSSR publ., 1987.

Статья поступила в редакцию 18.10 .2013

Информация об авторах

МАРАХТАНОВ Михаил Константинович (Москва) - доктор технических наук, профессор, зав. кафедрой «Плазменные энергетические установки». МГТУ им. Н.Э. Баумана (105005, Москва, Российская Федерация, 2-я Бауманская ул., д. 5, стр. 1, e-mail: mkm@power.bmstu.ru).

КЛИМЕНКО Георгий Константинович (Москва) - кандидат технических наук, доцент кафедры «Плазменные энергетические установки». МГТУ им. Н.Э. Баумана (105005, Москва, Российская Федерация, 2-я Бауманская ул., д. 5, стр. 1, е-таil: gkk@power.bmstu.ru).

ЧЖО Вин Наинг (Москва) - аспирант кафедры «Плазменные энергетические установки». МГТУ им. Н.Э. Баумана (105005, Москва, Российская Федерация, 2-я Бауманская ул., д. 5, стр.1, e-mail: kwn.bmstu@gmail.com).

\section{Information about the authors}

MARAKHTANOV Mikhail Konstantinovich (Moscow) - Dr. Sc. (Eng.), Professor, Head of «Plasma Power Plants» Department. Bauman Moscow State Technical University (BMSTU, building 1, 2-nd Baumanskaya str., 5, 105005, Moscow, Russian Federation, e-mail: mkm@power.bmstu.ru).

KLIMENKO Georgiy Konstantinovich (Moscow) - Cand. Sc. (Eng.), Associate Professor of «Plasma Power Plants» Department. Bauman Moscow State Technical University (BMSTU, building 1, 2-nd Baumanskaya str., 5, 105005, Moscow, Russian Federation, e-mail: gkk@power.bmstu.ru).

KYAW Win Naing (Moscow) - Post-Graduate of «Plasma Power Plants» Department. Bauman Moscow State Technical University (BMSTU, building 1, 2-nd Baumanskaya str., 5, 105005, Moscow, Russian Federation, e-mail: kwn.bmstu@gmail.com). 